consumption. Alcoholism: Climical and Experimental Research 1986;10: $535-44$

12 Pequignot G, Chabert C, Eydoux H, Courcowl MA. Augmentation du risque de cirrhose en fonction de la ration d'alcool. Revue de l'Alcoolisme 1974:20:191-202.

13 Wilson P. Drinking hahits in England and Wales. London: HMSO, 1980:11.

14 Van Eijk HG, Van Neort WL, Dubclaar ML, Van Der Heul G. The microheterogeneity of human transferrin in biological fluids. Clin Chim Acto 1983:132:167-71.

15 Chalmers DM, Rinsler MG, MacDermott S, Spicer CC, Levi AJ. Biochemical and hacmatological indicators of excessive alcohol consumption. (iu 981:22:992-6.

16 Chossegros P, Steghens JP, Gravagna B, et al. Serum mitochondrial aspartate aminotransferase (mAST): an additional marker of chronic alcoholism J Hepatol 1988; 7 (suppl):S115.

17 Stibler H, Allgulander C, Borg S, Kiellin KG. Abnormal microheterogencit of transferrin in serum and cerebrospinal fluid in alcoholism. Acta Med Scand 1978;204:49-56.

Accepted 3I Hav 1989)

\title{
Pilot study of treatment of persistent auditory hallucinations by modified auditory input
}

\author{
Mark N Collins, Christine A Cull, \\ Lester Sireling
}

St George's Hospital

Medical School, London

Mark N Collins, MRCPSYCH, lecturer in psychiatry

\section{Springfield Hospital,} London

Christine A Cull, PHD, clinical psychologist

Psychiatric Unit, Barnet General Hospital, Barnet, Hertfordshire EN5 3DJ Lester Sireling, MRCPSYCH, consultant psychiatrist

Correspondence to: Dr Sireling.

BrMed f 1989;299:431-2
Persistent auditory hallucinations occur in several psychiatric conditions. Predictions that hallucinations will decrease with increased external auditory stimulation are supported by several case reports. ${ }^{1.3}$ Green's theory of auditory hallucinations in schizophrenia proposes a defect in interhemispheric transmission of language. ${ }^{+} \mathrm{He}$ suggested that wearing an earplug might reduce verbal input to the non-dominant hemisphere. Studies of this have produced conflicting results.

We assessed the therapeutic potential of various techniques for modifying external auditory input in a patient suffering from intractable auditory hallucinations.

\section{Patient, methods, and results}

The patient was a 53 year old woman who had been an inpatient continuously for 14 months before this study. She had been admitted with delusions and first complained of hearing voices three months after admission. The voices discussed her in the third person and made critical comments about her. They were present for many hours each day. Treatment with neuroleptics, antidepressants, lithium, and carbamazepine failed to suppress them. She had been admitted with psychosis on three previous occasions over 12 years.

She was asked to rate the duration of her auditory hallucinations over a baseline period of seven days. Ratings were made hourly from 9 am to $6 \mathrm{pm}$ with eight point scales and referred to the preceding 30 minutes. Eight experimental conditions were then assessed in random order on alternate days. Each condition was applied for two hours, between midday and $2 \mathrm{pm}$; ratings were made half hourly during the test and hourly afterwards for a further three hours. The test conditions were tapes of pure music (classical), music and speech (BBC Radio 1), boring speech (British Telecom speaking clock), and interesting speech (BBC Radio 4); a blank tape (control); and a hearing aid (right ear); earplug (left ear), and earplug (right ear). A portable cassette tape player with intra-aural headphones was used, allowing continuous play for two hours. All conditions were investigated while she was an inpatient on the same ward, and no other changes were made to her treatment.

She had normal hearing and was right handed. Ratings were consistent over the seven baseline days. The figure shows the results. The tapes of music, music and speech, and interesting speech reduced the hallucinations whereas the blank tape had little effect. The reduction was not sustained beyond the test with music or music and speech, but the effect of interesting speech persisted. An earplug in the left ear made little difference, but when an earplug was used in the right ear the hallucinations disappeared after the test but not during it. Hallucinations temporarily stopped while and after she wore a hearing aid.
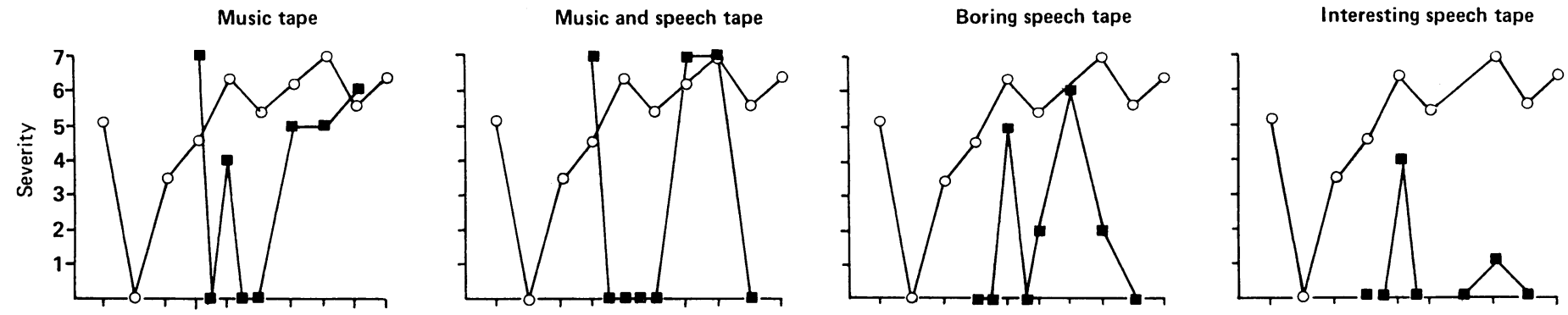

Blank tape

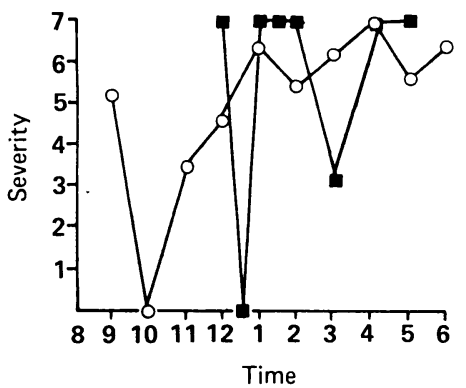

Hearing aid

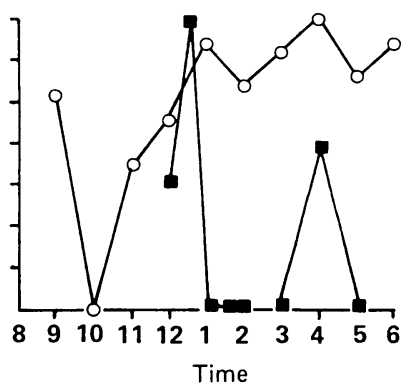

Earplug in left ea

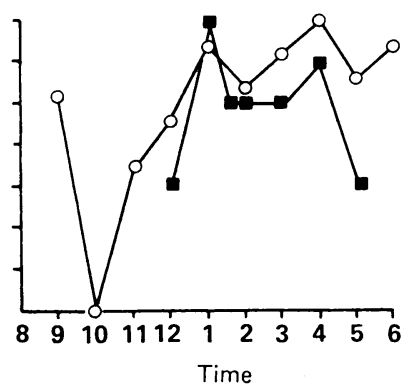

Ratings of hallucinations $(0=$ none, $7=$ continuous $)$ during and after each of eight conditions applied between 12 am and 2 pm. -

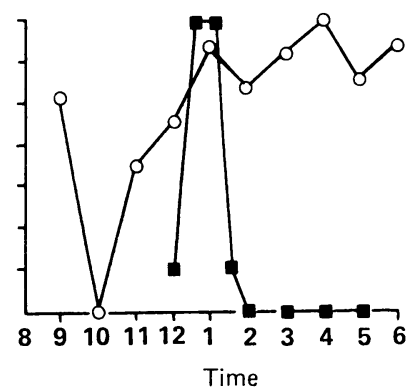

Earplug in right ea 
Her clinical improvement was such that she bought her own cassette player and was able to leave hospital taking reduced doses of drugs. She continued to listen to tapes when troubled by voices. At nine months' follow up she had a part time job and was using the cassette player on most days.

\section{Comment}

Our results provide tentative support for the hypothesis that increased external auditory stimulation reduces the severity of persistent auditory hallucinations. The response to the use of earplugs did not support Green's hypothesis. ${ }^{+}$Our patient's hallucinations spontaneously disappeared every morning at $10 \mathrm{am}$. We surmise that this was caused by her concentrating on ward based occupational therapy that started then. The clinical outcome in this patient was impressive, though conclusions can be only tentative.
Using a portable cassette player has the advantages of being cheap, simple, safe, non-invasive, and socially acceptable, and the patient is given a degree of personal control over distressing symptoms.

We thank Dr J Hollyman for permission to study her patient. The study was supported by a grant from the South West Thames Regional Health Authority's locally organised research scheme.

1 Falloon IRH, Talbot RE. Persistent auditory hallucinations: coping mechanisms and implication for management. Psychol Med 1981;11:329-39. Margo A, Hemsley DR, Slade PD. The effects of varying input on schizophrenic hallucinations. Br f Psychiatry 1981;139:122-7.

3 Feder R. Auditory hallucinations treated by radio headphones. Am 7 Psychiatry 1982;139:1 188-90.

4 Green P. Interhemispheric transfer in schizophrenia: recent development. Behavioural Psychotherapy 1978;6:105-10.

5 Morley $S$. Modification of auditory hallucinations: experimental studies of headphones and earplugs. Behavioural Psychotherapy 1987;15:240-51.

(Accepted 16 May 1989)

\title{
Steroid aerosols and cataract formation
}

\author{
Martin B Allen, Simon G Ray, A Gordon Leitch, \\ Baljean Dhillon, Barry Cullen
}

\begin{abstract}
Chest Unit, City Hospital, Edinburgh E10 5SB

Martin B Allen, MRCP, registrar

Simon G Ray, MRCP, registrar A Gordon Leitch, FRCP, consultant physician
\end{abstract}

\section{Princess Alexandra Eye} Pavilion, Edinburgh

Baljean Dhillon, FRCS, senior registrar

Barry Cullen, FRCS, consultant ophthalmologist

Correspondence to:

Dr M B Allen, Chest Unit, Killingbeck Hospital, Leeds LS14 6UQ.

BrMed f 1989;299:432-3
Posterior subcapsular cataract is a well recognised complication of treatment with oral corticosteroids, the incidence increasing with both dose and duration of treatment. Over $10 \mathrm{mg}$ of prednisolone per day for one year may be necessary for cataracts to develop, but this may be a conservative estimate. ${ }^{12}$ Inhaled steroids have been available in Britain since the early 1970 s and there is little evidence to implicate them in the development of cataracts. ${ }^{3}$

We have recently seen three patients whose asthma was treated with inhaled beclomethasone dipropionate and small total doses of oral steroids over several years and who developed posterior subcapsular cataract.

\section{Case reports}

Details of the patients are summarised in the table. Apart from the inhaled beclomethasone dipropionate, the only steroids the patients received were short reducing courses of oral prednisolone. Clinical examination showed no features associated with chronic use of steroids, and all three had normal fasting blood glucose concentrations. Full ophthalmological assessment showed normal intraocular tensions and no other reasons for the development of cataracts.

\section{Comment}

Cataracts have been described in patients with asthma who received substantial doses of oral steroids. In 1966 posterior subcapsular cataracts were identified in $3 \%$ of 265 asthmatic patients and in $32 \%$ of 406 patients with rheumatoid arthritis. ${ }^{1}$ A recent review confirmed this discrepancy, subcapsular cataracts occurring in $9 \%$ of patients with asthma, $18 \%$ with rheumatoid arthritis, and over $40 \%$ either with systemic lupus erythematosus or after renal transplantation. ${ }^{2}$ The lower incidence in asthmatic patients was thought to be due to a lower total dose of steroids, their younger ages, and the intermittent reducing regimens used. Children and young adults (aged less than 20 years) may be at greater risk of developing posterior subcapsular cataract: $29 \%$ of children taking steroids had cataracts, some occurring after only four months' treatment. ${ }^{24}$

As our patients had received fairly small doses of oral prednisolone the cataracts might have occurred by chance. Little information is available on the incidence and prevalence of posterior subcapsular cataract. A report in 1966 suggested a frequency of $0.6 \%$ in adults aged between 50 and 60 years. ${ }^{1}$ In $1977-81$ posterior subcapsular cataracts were found in nine of 760 unselected patients from a general practitioner's list who underwent a full ophthalmological examination. Routine ophthalmological practice indicates that most of these nine patients would have had factors predisposing them to development of cataracts, suggesting that unexplained posterior subcapsular cataract is uncommon ( $\mathrm{J}$ Cuthbert, personal communication).

Thus the relation between steroid treatment and development of posterior subcapsular cataract is complex, being related to patients' age, total dose of steroids and how often they were given, and probably the underlying medical condition. Some early cataracts regress after steroids are stopped, and susceptibility varies to the ophthalmological effects of steroids, as seen in glaucoma. ${ }^{1+5}$

In our three patients the only explanation for the development of cataracts was the steroid treatment. Oral steroids may have been responsible for the initial

Details of patients receiving inhaled and oral steroids who developed posterior subcapsular cataract

\begin{tabular}{|c|c|c|c|}
\hline & Case 1 & Case 2 & Case 3 \\
\hline Age (years) & 52 & 40 & 47 \\
\hline Sex & Female & Female & Female \\
\hline Duration of asthma (years) & 10 & 10 & 2 \\
\hline Dose of inhaled beclomethasone dipropionate & $400 \mu \mathrm{g} /$ day & $400 \mu \mathrm{g} /$ day & $\begin{array}{l}400 \mu \mathrm{g} / \text { day for } 1 \text { year; } \\
1500 \mu \mathrm{g} / \text { day for } 1 \text { year }\end{array}$ \\
\hline Estimated total intake of prednisolone & $\lg (3$ courses $)$ & $1.6 \mathrm{~g}(11$ courses $)$ & $540 \mathrm{mg}$ ( 3 courses $)$ \\
\hline Time since prednisolone last taken & 3 years & 6 months & 2 years \\
\hline Ophthalmological findings & Bilateral posterior subcapsular cataract, right $>$ left & Dense right cataract, left posterior subcapsular cataract & $\begin{array}{l}\text { Bilateral posterior } \\
\text { subcapsular cataract }\end{array}$ \\
\hline Visual acuities (with spectacles normally worn) & Right eye: hard movements; left eye: $6 / 9$ & Right eye: light only; left eye: $6 / 9$ & Right eye: $6 / 12$; left eye: $6 / 12$ \\
\hline Action & $\begin{array}{l}\text { Extraction of bilateral cataract and implantation of } \\
\text { intraocular lens }\end{array}$ & $\begin{array}{l}\text { Extraction of right cataract and implantation of } \\
\text { intraocular lens }\end{array}$ & Observation \\
\hline
\end{tabular}

